Short Communication

\title{
PREVALENCE OF TOBACCO CONSUMPTION IN A RURAL COMMUNITY OF BANGLADESH
}

\author{
Shaila Ahmed, Masuma Akter, Rishad Mahzabeen, Samia Sayeed, Hasina Momtaz, MA Sayeed \& \\ IM-4 MBBS students (Batch B) \\ Department of Community Medicine, Ibrahim Medical College, Shahbagh, Dhaka
}

\begin{abstract}
This cross sectional study was conducted in a rural community of Sreepur Thana during the month of November 2007. The objective of this study was to estimate the prevalence of tobacco consumption in the study area and observe some other associated variables. Respondents of both sexes aged 15 years and above were considered. The estimated sample size was 550 out of which 426 were found to be consumers of tobacco. Majority of the study population were males (68.4\%). Illiteracy was found in $34.7 \%$ of the respondents. Most of them had some type of small business $(38.2 \%)$ and a monthly expenditure between Tk.3001-6000 in 44\% of the households. Prevalence of tobacco usuer was estimated to be $77.5 \%$. Of them, $59 \%$ were smokers and $41 \%$ chewers. The most common form of smoking and chewing was found to be cigarette (69\%) and jarda (94.6\%) respectively. A large percentage of the respondents (94\%) knew about the adverse health effects caused by consumption of tobacco.
\end{abstract}

Ibrahim Med. Coll. J. 2008; 2(2): 58-60

Key Words: Tobacco consumption, smoking, rural community.

\section{Introduction}

Consumption of tobacco is a major risk factor for mortality. Data show that one in two smokers will die from a tobacco-related disease. ${ }^{1}$ Tobacco kills over four million people every year and by 2020 this is projected to rise to 8.4 million. Over $70 \%$ of these deaths will occur in developing countries ${ }^{2}$. Tobacco consumption is amongst the largest preventable causes of death today. Bringing down this consumption rate to save lives has been declared a public health priority by the WHO.

Tobacco is derived from the plant Nicotiana tabacum. The leaves of the plant is prepared for smoking, chewing, etc., by being dried, cured, and manufactured in various ways. Smoking is not only associated with lung cancer but is also linked to cardiovascular diseases, tuberculosis, and chronic respiratory diseases. ${ }^{3}$ Although about half of Bangladeshi men and one-fifth of women use tobacco in either smoking or in a smokeless form, awareness about its harmful effects is low. ${ }^{4}$
Tobacco consumption is often found to be disproportionately higher among lower socioeconomic groups. ${ }^{5}$ The gaps in tobacco consumption need to be examined to see which people are most likely to consume tobacco and which areas are more likely to have higher tobacco consumption. Such analyses are critical for designing policies and interventions aimed at achieving overall reductions in tobacco consumption.

\section{Materials and Methods}

This cross sectional study was done in four purposively selected villages in Sreepur union of Gazipur district from $20^{\text {th }}$ November to $2^{\text {nd }}$ December 2007 as a part of the residential field site training (RFST) program of medical students of IMC.

The study population consisted of both men and women aged 15 years and above and the estimated sample size was 550. Regular smokers and chewers (those

Address for Correspondence:

Dr. Shaila Ahmed, Associate Professor, Department of Community Medicine, Ibrahim Medical College 
who smoked or chewed at least once daily) were used as prevalence indicators. Information was collected from the respondents by face to face interview using a pre tested questionnaire. It included variables related to their socio demographic condition, smoking and chewing habits, knowledge and awareness about the adverse health hazards etc.

\section{Results}

Table 1 shows that half of the respondents were aged between 31-60 years with the majority being males $(68.4 \%)$. Nearly $35 \%$ respondents were found to be illiterate and the percentage of respondents having primary and secondary level education was almost same (22\%). Regarding occupation, $38.2 \%$ were involved in some type of small business while $27.4 \%$ were housewives. Tin roofed houses were the most

Table-1: Socio demographic information of the study population $(n=550)$

\begin{tabular}{|c|c|c|}
\hline Variables & ( n) & $\%$ \\
\hline \multicolumn{3}{|l|}{ Age } \\
\hline $15-30 \mathrm{yrs}$ & 226 & 41.1 \\
\hline $31-60$ yrs & 275 & 50.0 \\
\hline$>60 \mathrm{yrs}$ & 49 & 8.9 \\
\hline \multicolumn{3}{|l|}{ Sex } \\
\hline Male & 376 & 68.4 \\
\hline Female & 174 & 31.6 \\
\hline \multicolumn{3}{|l|}{ Education } \\
\hline Illiterate & 191 & 34.7 \\
\hline Can Read \& Write & 73 & 13.3 \\
\hline Primary & 123 & 22.4 \\
\hline Secondary & 124 & 22.5 \\
\hline Above & 39 & 7.1 \\
\hline \multicolumn{3}{|l|}{ Occupation } \\
\hline Farmer & 81 & 14.7 \\
\hline Service & 57 & 10.4 \\
\hline Housewife & 151 & 27.4 \\
\hline Day labourer & 51 & 9.3 \\
\hline Small Business & 210 & 38.2 \\
\hline \multicolumn{3}{|l|}{ Housing } \\
\hline Tin roof & 339 & 61.6 \\
\hline Kacha & 157 & 28.5 \\
\hline Pucca & 54 & 9.9 \\
\hline \multicolumn{3}{|l|}{ Sanitary Latrines } \\
\hline Present & 478 & 86.9 \\
\hline Absent & 72 & 13.1 \\
\hline \multicolumn{3}{|l|}{ Monthly expenditure } \\
\hline Tk 0-3,000 & 187 & 34.0 \\
\hline Tk 3,001-6,000 & 241 & 43.8 \\
\hline Tk 6,001-10,000 & 122 & 22.2 \\
\hline
\end{tabular}

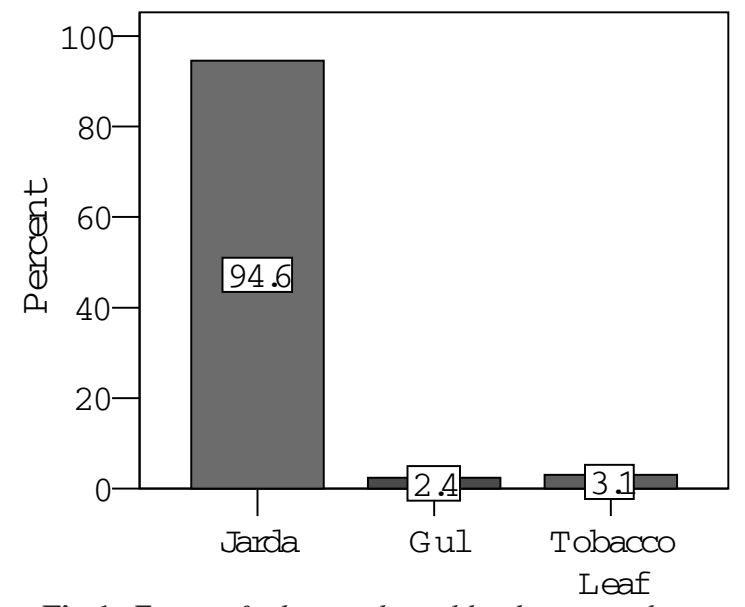

Fig-1. Forms of tobacco chewed by the respondents

common type found in that area $(61.6 \%)$ and sanitary latrine was present in nearly $87 \%$ of them. Monthly expenditure was between Tk. 3001-6000 in $44 \%$ of the respondents.

Prevalence of tobacco user in the study area was $77.5 \%$. Of them, $59.1 \%$ being smokers and $41 \%$ chewers. Among the smokers, majority of them were males (98.4\%). Chewing habit was also found to be prevalent among $64.1 \%$ females.

Among the smokers, the most popular form of smoking was cigarette (69.1\%). In those who were found to be chewing tobacco, it was found that chewing 'jarda' was almost universal $(94.6 \%)$ while a minute percentage chewed 'gul' and tobacco leaf (Fig-1).

About $42 \%$ of the smokers puffed 6-20 sticks daily while the frequency of chewing was 1-5 times a day in $59 \%$ of them as shown in Table 2. A large percentage of the respondents (94\%) knew about the adverse health effects of tobacco consumption while the rest $6 \%$ had no idea about the ill effects.

Table-2: Frequency of tobacco consumption $(n=426)$

\begin{tabular}{l|c|c}
\hline Variables & $\mathbf{n}$ & $\mathbf{\%}$ \\
\hline Smoking (sticks per day) & & \\
6 & 80 & 31.3 \\
$6-20$ & 107 & 41.8 \\
$\quad>20$ & 69 & 27.0 \\
Chewing (times per day) & & \\
1-5 & 173 & 58.6 \\
$6-10$ & 66 & 22.4 \\
$>10$ & 56 & 19.0 \\
\hline
\end{tabular}




\section{Discussion}

This cross sectional study was done in a rural community of Sreepur thana with an attempt to determine the prevalence and pattern of tobacco consumption, and to know whether the respondents had any knowledge regarding the bad health effects of this habit. A total of 550 respondents were interviewed, out of whom 426 were found to be consumers of tobacco.

Most of the people residing in the study areas were found to be illiterate (35\%) with only $22 \%$ having primary or secondary level education. Forty four percent of the households had a monthly expenditure of Tk.30016000. Majority of the houses were tin roofed (61.6\%) and sanitary latrine was present in $87 \%$ of them.

Prevalence of tobacco consumption found among the 15 years and above age group was $77.5 \%$. Smokers constituted $59.1 \%$ and chewers $41 \%$. The Bangladesh Demographic and Health Survey (BDHS) 2004 found the overall prevalence of tobacco consumption to be $59 \% .^{6}$ In another study conducted in 1995 to estimate the global prevalence, it was seen that smoking habit was highest in persons aged 30 to 49 years. Low- and middle-income countries accounted for $82 \%$ of the world's smokers. In East Asia and the Pacific, 32\% of the population aged 15 years and older were tobacco consumers. ${ }^{1}$

This study found that $69.1 \%$ of the smokers preferred cigarettes and the rest bidi. Jarda was the most popular form of chewing found among the chewers (94.6\%). BDHS 2004 concluded bidi smoking to be $29.6 \%$, cigarette smoking $27.8 \%$ and chewing betel quid with tobacco/jarda $17.5 \%$ respectively. A study conducted in India found 50 to $80 \%$ of the smokers smoke bidis, and the remainder smoke cigarettes. ${ }^{7}$

Forty two percent smokers consumed 6-20 sticks daily as estimated in this study while frequency of chewing was 1-5 times a day in about $59 \%$ of chewers. Surprisingly it was seen that majority of the respondents (94\%) knew about the adverse health effects of tobacco consumption although they made no efforts to quit the habit. This figure was found to be $80 \%$ in another study conducted among the population of some developing counties. ${ }^{8}$

\section{Conclusion and Recommendation}

This cross sectional study was a limited attempt in a rural community of Bangladesh to estimate the prevalence of tobacco consumption and some other associated variables. The calculated prevalence was $77.5 \%$ which is quite alarming compared to some previous data. It indicates that both communicable and non communicable disease burden will rise in the future. Although majority of the consumers knew about the adverse health effects of smoking and chewing tobacco, they were reluctant to give up the habit. This study suggests that planning anti-smoking campaigns and health education programs for the general mass needs to be geared up. Further in-depth studies to find out the factors related to tobacco consumption and inability to quit, along with the health hazards present among the consumers will be of great value.

\section{References}

1. Jha P, Ranson MK, Nguyen N, Yach D. Estimates of Global and Regional Smoking Prevalence in 1995, by Age and Sex. Am J Public Health 2002; 92(6): 1002-1006.

2. Peto R, Lopez AD. The Future Worldwide Health Effects of Current Smoking Patterns. Global Health in the 21st Century. New York, NY: Jossey-Bass 2000; 154-161.

3. Murray CJ, Lopez AD. Mortality by cause for eight Regions of the World: Global Burden of Disease Study. Lancet 1997; 349: 1269-1276.

4. Ahmed S, Rahman A, Hull S. Use of Betel Quid and Cigarettes Among Bangladeshi patients in an Inner-City Practice: Prevalence and Knowledge of Health Effects. Br J Gen Pract 1997; 47(420): 431-434.

5. Summers RM, Williams SA, Curzon ME. The Use of Tobacco and Betel Quid among Bangladeshi Population in West Yorkshire. Community Dent Health 1994; 11(1):12-16.

6. Bangladesh Demographic and Health Survey 2004. (Dhaka, National Institute of Population and Training, Mitra and Associates, ORC Macro).

8. Narayan KM, Chadha SL, Hanson RL, Tandon R. Prevalence and Patterns of Smoking in Delhi: cross sectional study. BMJ 1996; 312: 1576-1579.

9. Peto R, Lopez AD, Boreham J, Thun M, Heath C. Mortality from Smoking in Developing Countries, 1950-2000. Oxford: Oxford University Press, 1994.

The following students of IM-4B were involved in this study: Mariya Tabassum, Arifa Akhter, Montaha Jamal, Ishita Mou, Shanjida Hoque, Nurun Nahar, Ishrat Zebin, Golam Moinuddin, Most. Touhida Shirin, Maftahul Jannaty, Tamanna Hossain

Editor's Note: In continuation of our interest in publishing articles resulting from our Residential Field Site Training (RFST) Programme for the $4^{\text {th }}$ year MBBS students, we are publishing this article. Articles resulting from RFST Programme were published in our previous issues. 